\title{
EVALUACIÓN DE Azotobacter vinelandii Y Pseudomonas denitrificans EN Dioscorea rotundata EN CONDICIONES DE CAMPO
}

\author{
Sánchez López, D. B. ${ }^{1}$; Pérez Pazos, J. V. ${ }^{1}$; Luna Castellanos, L. L. ${ }^{1}$; \\ García Peña, J. A. ${ }^{1}$ \& Espitia Montes, A. A. ${ }^{1}$
}

\begin{abstract}
RESUMEN
Las rizobacterias de vida libre o asociativas promueven el crecimiento vegetal, fijan nitrógeno y sintetizan fitohormonas. La combinación de estos mecanismos contribuye a mejorar la eficiencia en el uso de fertilizantes nitrogenados y aumentar la productividad de los cultivos. El objetivo de esta investigación fue evaluar el efecto de Azotobacter vinelandii DVS9 y Pseudomonas denitrificans DVS10 bajo diferentes niveles de fertilización química nitrogenada (50\% y 75\%) sobre el rendimiento y calidad nutricional de los tubérculos de Dioscorea rotundata. El estudio se realizó en el municipio de Morindó, Córdoba (Colombia), empleando un diseño experimental completamente aleatorizado con un arreglo factorial aumentado $3 \times 2+2$, con 3 repeticiones. Los resultados obtenidos indican que la inoculación de la cepa Pseudomonas denitrificans DVS10 redujo un $25 \%$ la fertilización nitrogenada el cultivo de ñame espino, asimismo, esta bacteria produjo incrementos significativos en los contenidos de proteína y fibra cruda del tubérculo.
\end{abstract}

Palabras clave: Rizobacterias, fertilizantes, rendimiento, tubérculos.

\begin{abstract}
Evaluation of Azotobacter vinelandii and Pseudomonas denitrificans in Dioscorea rotundata in field conditions.

The free-living or associative rhizobacteria promote plant growth, fix nitrogen and synthesize phytohormones. The combination of these mechanisms contributes to improve the efficiency in the use of nitrogen fertilizers and increase the productivity of crops. The objective of this investigation was to evaluate the effect of Azotobacter vinelandii DVS9 and Pseudomonas denitrificans DVS10
\end{abstract}

1.- Corporación Colombiana de Investigación Agropecuaria (AGROSAVIA). Centro de Investigación Turipaná. Km 13 vía Montería-Cereté, Colombia. Email: dbsanchez@corpoica.org.co Código Orcid: 0000-00019715-4097".

Manuscrito recibido el 12 de septiembre de 2017 y aceptado para su publicación el 3 de julio de 2018.

Sánchez López, D.B.; Pérez Pazos, J. V.; Luna Castellanos, L.L.; García Peña, J.A.; Espitia Montes, A.A. Evaluación de Azotobacter vinelandii y Pseudomonas denitrificans en Dioscorea rotundata en condiciones de campo. FAVE - Ciencias Agrarias 17 (1): 35-43.

CC BY-NC-SA 4.0 (c) (i) (-) 


\section{B. Sánchez López et al.}

under different levels of nitrogen chemical fertilization ( $50 \%$ and $75 \%$ ) on the yield and nutritional quality of the tubers of Dioscorea rotundata. The study was conducted in the municipality of Morindó, Córdoba (Colombia), using a completely randomized experimental design with an increased factorial arrangement $3 \times 2+2$, with 3 repetitions. The results obtained indicate that the inoculation of the strain Pseudomonas denitrificans DVS10 reduced the nitrogen fertilization by $25 \%$, the cultivation of yam hawthorn, likewise, this bacterium produced significant increases in the protein and crude fiber contents of the tuber.

Key words: Rhizobacteria, fertilizers, yield, tubers.

\section{INTRODUCCIÓN}

El ñame (Dioscorea sp.) son plantas dioicas del género Dioscorea, pertenecen a la familia Dioscoreaceae y producen tubérculos y bulbillos (tubérculos aéreos) de importancia económica y medicinal (33). La familia Dioscoreaceae comprende seis géneros, de los cuales, Dioscorea es el mayor. Cerca de 600 especies de Dioscorea han sido identificadas y doce son comestibles (8). Dentro de este género, las especies comestibles y de valor comercial se identifican: Dioscorea alata, D. rotundata, D. esculenta, $D$. bulbifera y $D$. cayenensis. $D$. alata es común en Asia, en tanto, D. rotundata y D. cayenensis son cultivadas principalmente en África (25). El ñame es uno de los tubérculos tropicales más cultivados en la región del Caribe Colombiano, constituye parte de la dieta de sus pobladores y es fuente de ingresos económicos para los productores $(31 ; 16)$. En el 2014, Colombia tuvo una producción de 10,4 t. ha- ${ }^{-1}$ situándose como el primer productor de ñame en América, superando a Brasil y Cuba en un $8 \%$ y $55 \%$ respectivamente (12). Del total de la producción nacional para el 2014 el $76 \%$ proviene principalmente de la región del Caribe Colombiano (3), donde este cultivo representa una fuente de seguri- dad alimentaria e ingresos económicos a pequeños productores. A nivel mundial el consumo de fertilizantes nitrogenados ha aumentado en las prácticas agrícolas, así como el costo y la contaminación ecológica que estos producen $(13 ; 39)$, sin embargo, en las dos últimas décadas se ha revelado el uso de tecnologías nutricionales como es el caso de los biofertilizantes que representan una importante alternativa para reducir la demanda de fertilización química y mejorar la productividad y calidad de los cultivos.

Los biofertilizantes están compuestos por microorganismos entre los que se destacan las bacterias, Kloeppler y Schroth (20) las designaron como Rizobacterias Promotoras del Crecimiento Vegetal (PGPRs, por sus siglas en inglés), las cuales a través de una amplia variedad de mecanismos moleculares (26), son capaces de estimular el crecimiento, mejorar la salud vegetal, favorecen la producción, rendimiento y calidad de los cultivos $(19 ; 34 ; 35)$. Entre los géneros más destacados se encuentran Arthrobacter, Azospirillium, Azotobacter, Serratia, Azoarcus, Bacillus, Burkholderia, Enterobacter, Erwinia, Gluconacetobacter, Klebsiella, Pseudomonas, Beijerinckia, Rhizobium, Burkholderia, Streptomyces etc. $(6 ; 27 ; 38)$. Entre los mecanismos que estas bacterias utilizan para estimular el 
crecimiento vegetal se encuentra la solubilización de fosfatos (37), la producción de fitohormonas y la fijación de nitrógeno. Estos mecanismos bacterianos producen efectos directos sobre el metabolismo de las plantas, la absorción de minerales, el desarrollo radicular, la actividad enzimática y ayudando a otros microorganismos benéficos a ejercer su acción sobre las plantas (5). Entre otras de las propiedades, algunas PGPRs presentan la capacidad de control biológico, generando compuestos capaces de inhibir el crecimiento de fitopatógenos (10). La bacteria Pseudomonas denitrificans es un microorganismo capaz de adaptarse, colonizar y persistir en la rizósfera de la planta, lo cual favorece su crecimiento y desarrollo (28); esta bacteria actúa en la interfaz de las raíces promoviendo el desarrollo de estas, debido a la producción de auxinas (11). El Azotobacter vinelandii es una bacteria de vida libre, que vive del suelo y es considerado un fijador de nitrógeno atmosférico (34), ha sido especialmente útil para determinar las estructuras y los mecanismos de diferentes enzimas nitrogenasas y pueden funcionar en ambientes óxicos y las interacciones de la fijación de nitrógeno con otros aspectos del metabolismo, a su vez, producir dos polímeros de importancia biotecnológica, como el poliéster intracelular poli-3-hidroxibutirato y el polisacárido extracelular de la familia de polihidroxialcanoatos, posee un gran potencial para nuevos descubrimientos en muchos campos y aplicaciones comerciales $(14 ; 29)$. El objetivo de este trabajo fue evaluar el efecto de las cepas bacterianas con diferentes niveles de fertilización química nitrogenada en el cultivo de ñame espino establecido en la localidad de Morindó- Córdoba.

\section{MATERIALES Y MÉTODOS}

\section{Localización}

El ensayo se realizó bajo condiciones de campo en el municipio de Morindó, departamento de Córdoba (Colombia); ubicado a $08^{\circ} 54^{\prime}$ ' 3" latitud norte $76^{\circ} 6^{\prime} 30^{\prime \prime}$ longitud Oeste, altitud de $126 \mathrm{msnm}$, esta zona corresponde a bosque seco tropical con temperatura media de $27,5^{\circ} \mathrm{C}$, humedad relativa del $85 \%$ y precipitación anual de $1100 \mathrm{~mm}$. El suelo se caracteriza por presentar una textura franco-arcillosa, contenido de materia orgánica de 1,48\%, pH $(6,4)$, contenido de fósforo $17,89 \mathrm{ppm}$ y potasio $0,79 \mathrm{ppm}$.

\section{Material vegetal}

El material vegetal correspondió a plántulas de ñame espino (Dioscorea rotundata), obtenidas a partir de mini secciones de tubérculo de $50 \mathrm{~g}$, las cuales fueron sembradas en eras de 1,0 $\mathrm{m}$ de largo por 10,0 $\mathrm{m}$ de ancho en condiciones de vivero. El sustrato fue desinfectado mediante solarización, contenía arena y tierra negra (relación 1:1). Las plántulas fueron trasplantadas a campo por el método de raíz desnuda 30 días después de la emergencia.

\section{Diseño experimental}

La investigación se realizó bajo un diseño experimental de bloques completos al azar con un arreglo factorial aumentado $3 \times 2+2$ y tres repeticiones por tratamiento. El primer factor lo constituyen las cepas bacterianas seleccionadas y caracterizadas a partir de cultivos de ñame (33) distribuidas en tres niveles (Azotobacter vinelandii DVS9, Pseudomonas denitrificans DVS10 y mezcla); el segundo factor corresponde a la fertilización nitrogenada con dos niveles 
(50\% y $75 \%$ ); adicionalmente se evaluaron dos tratamientos sin inoculación denominados como testigos (absoluto y químico). Los tratamientos evaluados fueron los siguientes: T1: Testigo absoluto; T2: Testigo químico 100\% Fertilización Nitrogenada (FN); T3: A. vinelandii DVS9+50 \% FN; T4: A. vinelandii DVS9+75 \% FN; T5: $P$. denitrificans DVS10+50\% FN; T6: P. denitrificans DVS10+75 \% FN; T7: A. vinelandii DVS9 + P. denitrificans DVS10+50\% FN; T8: A. vinelandii DVS9 + P. denitrificans DVS10+75\% FN. En total se establecieron 24 unidades experimentales, cada una estuvo conformada por 5 surcos de 7,2 $\mathrm{m}$ de largo por 1,0 $\mathrm{m}$ entre surco y surco para un área total de $36 \mathrm{~m}^{2}$. La densidad de siembra utilizada fue de 16,666 plantas/ha.

\section{Inoculación de rizobacterias y fertilización química}

Los requerimientos de fertilización se realizaron con base en los resultados de análisis del suelo, presentándose una demanda de fósforo aplicado como fosfato diamónico (DAP), 20,0 kg/ha al momento del trasplante y potasio aplicado como cloruro de potasio $(\mathrm{KCl}), 30,0 \mathrm{~kg} / \mathrm{ha}$ a los 30 días después del establecimiento. Estos minerales se aplicaron bajo las mismas condiciones para todos los tratamientos. La fertilización nitrogenada se realizó con urea de forma fraccionada, empleando una dosis total de $216,5 \mathrm{~kg} / \mathrm{ha}$. La primera fracción correspondiente al $20 \%$ a los 25 días de establecido el ensayo, la segunda (30\%) 35 a 40 días del trasplante y la tercera dosis (50\%) 50-55 días de plantado el cultivo en el sitio definitivo.
La inoculación de los microorganismos se realizó en la fase de trasplante a sitio definitivo y al momento de la aplicación de los fertilizantes químicos nitrogenados (Urea). Las plantas fueron inoculadas aplicando $10 \mathrm{ml}$ de la suspensión bacteriana directamente al suelo, al pie de cada planta. La concentración celular del inóculo bacteriano correspondió a $1 \times 10^{8}$ UFC. $^{-1}$ en medio Luria Bertani (LB) (g. $\mathrm{L}^{-1}$ : Peptona $(10,0)$, Extracto de levadura $(5,0)$, Cloruro

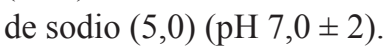

\section{Variables de respuesta}

La cosecha se realizó ocho meses después del trasplante. Se determinó el rendimiento total de los tubérculos y la composición bromatológica expresada en los parámetros: proteína (\%) (AOAC 960.52 (1), fibra cruda (\%) (ISO 6865) (18) (NTC 5122) (30), extracto etéreo (\%), (AOAC 920.39) (1) y la energía bruta de los tubérculos se determinó usando una bomba calorimétrica (Parr 6200, Parr Instrument Company, Moline, IL) y se expresó como Mcal $/ \mathrm{kg}$.

\section{Análisis estadístico}

Los datos de rendimiento y nitrógeno total en suelo se analizaron mediante un ANOVA y prueba de comparación de medias de Tukey $(\alpha \leq 0.05)$ bajo un diseño factorial aumentado $3 \times 2+2$. Para la composición bromatológica de la raíz reservante se realizó una prueba de comparación de medias de Tukey $(\alpha \leq 0.05)$, empleando el software SAS 9.4 (español). 


\section{RESULTADOS Y DISCUSIÓN}

Efecto de las Rizobacterias sobre el rendimiento de Dioscorea rotundata

El análisis de varianza de los datos de rendimiento indica que existe un efecto significativo de la interacción Cepa* Fertilización ( $p$-valor $=0,0106)$ en la variable de rendimiento, estos resultados sugieren que el rendimiento de ñame en la localidad de Morindó depende tanto de la inoculación bacteriana como del nivel de fertilización, estos resultados coinciden con lo encontrado para Ipomoea batatas por Yasmin y col. (40) quienes evaluaron el efecto de la inoculación con PGPRs en el cultivo de batata bajo diferentes niveles de fertilización nitrogenada y encontraron una interacción significativa de ambos factores que favoreció el aumento en el peso de la raíz en comparación con el testigo. Como se observa en la Figura 1, los rendimientos totales de tubérculos en las parcelas inoculadas con las cepas bacterianas fueron significativamente superiores en comparación al control no inoculado.

Resultados similares a los obtenidos en esta investigación se han reportado para otros tubérculos, Kumar y col. (22) en cultivos papa variedad Kufri Giriraj, encontraron rendimientos de 19,4 t. ha ${ }^{-1}$ con la mezcla de biofertilizantes (Azotobacter sp. y bacterias solubilizadoras de fósforo), valores superiores a los obtenidos en las plantas no tratadas. De igual forma, Abbas y col. (2), reportan en cultivos de papa bajo condiciones de campo que la aplicación de bio-preparados a base de mezclas de aislamientos bacterianos de naturaleza diazotrófica (Azospirrillum brasilense, Azotobacter chroococum, Bacillus polymyxa, Enterobacter agglomerans y Pseudomonas putida), incrementó el rendimiento de los tubérculos en un $18 \%$ con respecto a la fertilización de síntesis química y su efecto positivo fue consistente durante los ensayos de campo sucesivos.

El tratamiento T6 presentó diferencias estadísticamente significativas $(\alpha \leq 0.05)$ respecto al Testigo químico (T2) y el Tes-

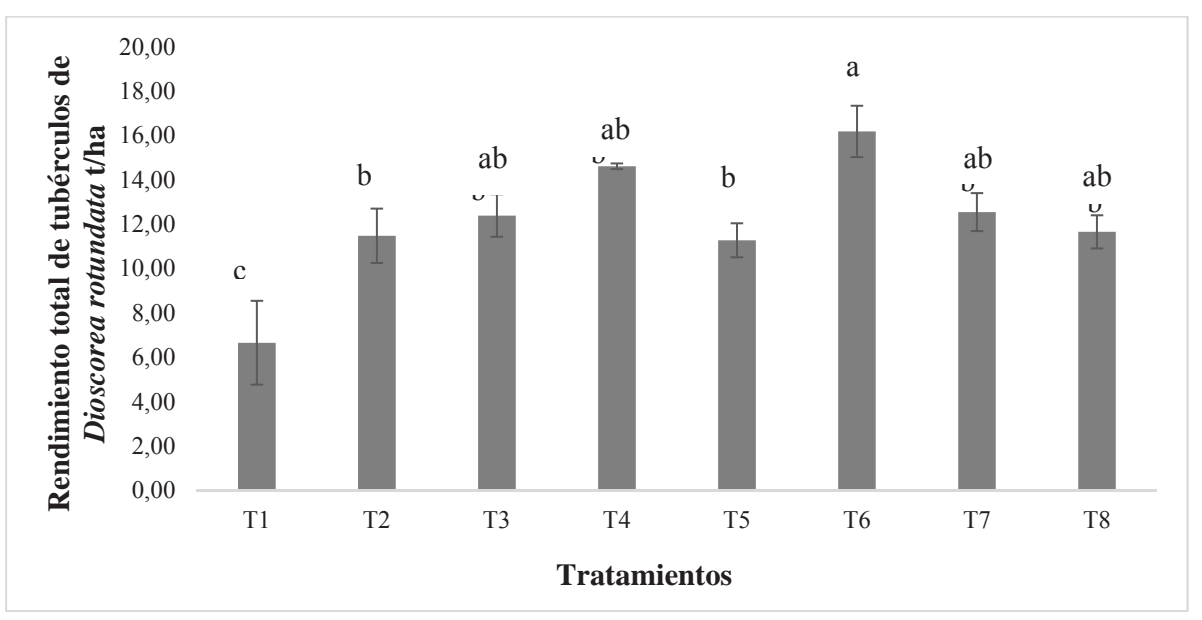

Figura 1. Comparación de medias entre cepas y fertilización química nitrogenada para la variable rendimiento total de tubérculos de Dioscorea rotundata. Las barras de error representan la desviación estándar. Las letras representan diferencias estadísticamente significativas ( $\alpha \leq 0.05)$. 
tigo absoluto (T1) superando en 4,71 t. ha-1 los rendimientos del tratamiento con $100 \%$ FN y 9,53 t. ha ${ }^{-1}$ al tratamiento con $0 \% \mathrm{FN}$ (Figura 1). El aumento en rendimiento de los tubérculos obtenidos con la inoculación de microorganismos puede atribuirse a una mejora en la disponibilidad de nutrientes por mecanismos directos como solubilización de fosfatos (23), mejor desarrollo de los sistemas de raíces y secreción de hormonas vegetales (4; 9). Ram (32), encontró que el aumento en el rendimiento de tubérculos de papa se vio favorecido de forma significativa por el tratamiento con bacterias solubilizadoras de fósforo (Pseudomonas strata) y bacterias fijadoras de nitrógeno (Azotobacter chroococum), las cuales pueden reducir un $25 \%$ del requerimiento de nitrógeno y fósforo en este cultivo. En el mismo sentido, Hernández (17) reportó en papa, que la inoculación de micorrizas, Pseudomonas cepacia y Pseudomonas fluorescens, generó una mayor producción de tubérculos, respecto al testigo con fertilización química.

\section{Efecto de las PGPRs sobre la calidad nutricional de los tubérculos de Dioscorea rotundata}

En relación con los resultados del análisis bromatológico realizado a los tubérculos obtenidos en el experimento, no se encontraron diferencias significativas $(\alpha \geq 0.05)$ entre tratamientos para los parámetros evaluados (excepto para la energía bruta); cabe resaltar que se obtuvieron incrementos en los contenidos de proteína y fibra cruda con el tratamiento T6 con respecto al testigo absoluto (Tabla 1).

Estudios realizados por Knowles y col. (22) reportaron que el contenido de proteínas en ñame espino (Dioscorea rotundata) fue del $6,8 \%$, valores superiores fueron obtenidos en en esta investigación (Tabla 1) alcanzando el máximo valor de $9,45 \%$ con el tratamiento T6, el cual registró un incremento del 2,12\% respecto al testigo absoluto. Estos resultados sugieren que la inoculación de PGPRs en el cultivo de ñame espino estimula una mejora en la calidad nutricional de

Tabla 1. Análisis Bromatológicos de tubérculos Dioscorea rotundata bajo inoculación con Azotobacter vinelandii y Pseudomonas denitrificans bajo diferentes niveles de fertilización química nitrogenada.

\begin{tabular}{|l|c|c|c|c|}
\hline \multirow{2}{*}{ Tratamientos } & Proteína & $\begin{array}{c}\text { Extracto } \\
\text { Etéreo }\end{array}$ & Fibra Cruda & Energía Bruta \\
\cline { 2 - 5 } & $\%$ & $\%$ & $\%$ & Mcal /Kg \\
\hline T1 & $7,33 \pm 0,83 \mathrm{a}$ & $0,16 \pm 0,06 \mathrm{a}$ & $2,34 \pm 0,28 \mathrm{a}$ & $4,15 \pm 0,17 \mathrm{ab}$ \\
\hline T2 & $8,58 \pm 1,39 \mathrm{a}$ & $0,14 \pm 0,02 \mathrm{a}$ & $2,17 \pm 0,25 \mathrm{a}$ & $4,26 \pm 0,02 \mathrm{ab}$ \\
\hline T3 & $6,89 \pm 0,77 \mathrm{a}$ & $0,33 \pm 0,38 \mathrm{a}$ & $1,83 \pm 0,69 \mathrm{a}$ & $4,49 \pm 0,26 \mathrm{a}$ \\
\hline T4 & $8,71 \pm 0,89 \mathrm{a}$ & $0,16 \pm 0,11 \mathrm{a}$ & $2,00 \pm 0,74 \mathrm{a}$ & $4,28 \pm 0,07 \mathrm{ab}$ \\
\hline T5 & $8,08 \pm 1,02 \mathrm{a}$ & $0,13 \pm 0,07 \mathrm{a}$ & $1,95 \pm 0,40 \mathrm{a}$ & $4,05 \pm 0,05 \mathrm{~b}$ \\
\hline T6 & $9,45 \pm 0,33 \mathrm{a}$ & $0,16 \pm 0,05 \mathrm{a}$ & $3,52 \pm 1,69 \mathrm{a}$ & $4,05 \pm 0,16 \mathrm{~b}$ \\
\hline T7 & $8,49 \pm 1,38 \mathrm{a}$ & $0,13 \pm 0,03 \mathrm{a}$ & $2,32 \pm 0,38 \mathrm{a}$ & $4,08 \pm 0,02 \mathrm{~b}$ \\
\hline T8 & $8,85 \pm 0,27 \mathrm{a}$ & $0,19 \pm 0,08 \mathrm{a}$ & $2,28 \pm 0,27 \mathrm{a}$ & $4,00 \pm 0,03 \mathrm{~b}$ \\
\hline
\end{tabular}

Medias con letras no comunes dentro de cada variable difieren estadísticamente según prueba de Tukey para $\alpha \leq 0.05(n=3)$. 
los tubérculos $(24 ; 15)$. En cuanto a los porcentajes de fibra cruda Bou Rached y col. (7), encontraron que el contenido de fibra cruda en Dioscorea trífida variedad blanca fue del $0,05 \%$ sin fertilización, así mismo, Knowles y col. (21) determinaron que el porcentaje de fibra cruda en tubérculos de Dioscorea rotundata fue del $1,1 \%$, este valor fue superado en esta investigación con el tratamiento T6 $(3,52 \%)$ que corresponde a la inoculación de la bacteria $P$. denitrificans DVS10 y un $75 \%$ de FN (Tabla 1). Con relación a los valores de energía bruta se encontraron diferencias estadísticas significativas $(\alpha \leq 0.05)$ entre los tratamientos evaluados, se observó que la mezcla de $A$. vinelandii DVS9 + 50\% FN incrementó de forma significativa $(4,49 \%)$ este parámetro, lo cual sugiere incrementos del valor nutricional de los tubérculos de ñame tratados con PGPRs en comparación con el Testigo absoluto y Testigo químico (T2).

\section{CONCLUSIONES}

El aumento en rendimiento de los tubérculos de ñame en la localidad de Morindó, Córdoba (Colombia) estuvo influenciado por la fertilización nitrogenada y el uso de cepas bacterianas con capacidad de promover el crecimiento. Con la incorporación de la bacteria $P$. denitrificans DVS10 a un $75 \%$ de FN en el plan de fertilización del cultivo de ñame espino se alcanzó el mayor valor de rendimiento y respecto a la calidad del tubérculo se presentaron los mayores porcentajes de proteína y fibra cruda, estos hechos sugieren que el uso de microorganismos representa una alternativa promisoria para incrementar el rendimiento y calidad del tubérculo en cultivos de Dioscorea rotundata en el Caribe Colombiano.

\section{AGRADECIMIENTOS}

Este estudio fue financiado por el Ministerio de Agricultura y Desarrollo Rural (MADR) de Colombia bajo el convenio TV16 con AGROSAVIA y al laboratorio de Microbiología Agrícola del Centro De Investigación Turipaná.

\section{BIBLIOGRAFÍA}

1- AOAC (Association of Official Analytical Chemists). 2010. Official methods of analysis of AOAC International. $17^{\circ} \mathrm{ed}$. AOAC International. Gaithersburg, MD, USA.

2- ABBAS, M. T.; HAMZA, M. A.; YOUSSEF, H. H.; YOUSSEF, G. H.; FAYEZ, M.; MONIB, M. Y HEGAZI, N. A. 2014. Bio-preparates support the productivity of potato plants grown under desert farming conditions of north Sinai: Five years of field trials. J. Adv Res. 5(1): 41-48.

3- AGRONET. 2016. Estadísticas área cosechada, producción y rendimiento de ñame. 19862014. Disponible en: http://www.agronet.gov. co/Paginas/default.aspx. Acceso: 07/09/2017.

4- BAISHYA, L.K.; GUPTA, V.K.; LAL, S.S.; DAS, B.K. Y KUMAR, M. 2005. Efecto of biofertilizers on growth and yield of potato in northern eastern hills of India. Pot J. 32(3-4): 242.

5- BASHAN, Y. Y HOLGUIN, G. 1998. Proposal for the division of plant growth-promoting rhizobacteria into two classifications: biocontrol-PGPB (plant growth-promoting bacteria) and PGPB. Soil Biol Biochem 30(8): 1225-1228.

6- BHATTACHARYYA, P. N. Y JHA, D.K. 2012. Plant growth- promoting rhizobacteria (PGPR): emergence in agriculture. World. J. Microbiol Biotech 28 (4): 1327-1350. 
7- BOU RACHED, L.; DE VIZCARRONDO, C. A.; RINCÓN, A. M. Y PADILLA, F. 2006. Evaluación de harinas y almidones de mapuey (Dioscorea trifida), variedades blanco y morado. archivos Latinoamericanos de Nutrición 56(4): 375- 383.

8- COURSEY, D.G. 1976. Yams; Dioscorea spp. In Simmonds, N.W. ed. Evolution of Crop Plants. London, Longmans. 70-74 pp.

9- DE CARVALHO COSTA, F. E. Y DE MELO, I. S. 2012. Endophytic and rhizospheric bacteria from Opuntia ficus-indica mill and their ability to promote plant growth in cowpea, Vigna unguiculata (L.) Walp. Afr. J. Microbiol Res 6(6):1345-1353.

10- DE-BASHAN, L. E.; HOLGUIN, G.; GLICK, B. R. Y BASHAN, Y. 2014. Bacterias promotoras de crecimiento en plantas para propósitos agrícolas y ambientales. (eds). Editorial Trillas. México. p 170-224.

11-EGAMBERDIYEVA, D.; DAVRANOV, K. D. Y HÖFLICH, G. 2001. Influence of growth-promoting bacteria from Uzbekistan and Germany on the growth and nutrient uptake of cotton and wheat on different soils. In: Horst W.J. et al. (eds) Plant Nutrition. Developments in Plant and Soil Sciences, vol 92. Springer, Dordrecht.

12- FAO. 2017. Yam production statistics 2014. Faostat. FAO. Roma. Disponible en: http:// www.fao.org/faostat/es/\#data/QC. Acceso: 07/09/2017.

13- GAMBLE, T. N.; BETLACH, M. R. Y TIEDJE, J. M. 1977. Numerically dominant denitrifying bacteria from world soils. J Appl Environ Microbiol. 33(4):926-939.

14- GARCÍA, A.; FERRER, P.; ALBIOL, J. CASTILLO, T.; SEGURA, D. Y PEÑA, C. 2018. Metabolic flux analysis and the NAD (P) H/NAD (P)+ ratios in chemostat cultures of Azotobacter vinelandii. Microb Cell Fact 17(1):1-13.
15- GONZALVO, S.; NIEVES, D.; LY, J.;MACÍAS, M.;CARÓN, M. Y MARTÍNEZ, V. 2001. Algunos aspectos del valor nutritivo de alimentos venezolanos destinados a animales monogástricos. Livestock Res. Rural Devel. 13(2). Disponible en: http://www.lrrd.cipav. org.co/lrrd13/2/gonz132 Acceso: 07/09/2017.

16- GUTIÉRREZ, J. B. 2001. Alimentos para la salud. Arbor 168 (661) :1-29.

17- HERNÁNDEZ, A. 2001. Manejo agronómico integral de sustratos, métodos de siembra y biofertilización en la producción sostenible de tubérculos-semilla de papa por semi1la sexual. Cultivos tropicales 22(2):21-27.

18- ISO 6865. International Organization for Standardization. 2002. Determination of crude fibre content - method with intermediate filtration. Méthode avec filtration intermédiaire.

19- JHA, C. K.; PATEL, B. Y SARAF, M. 2012. Stimulation of growth of Jatropha curcas by the plant growth promoting bacterium Enterobacter cancerogenus MSA2. World J. Microbiol. Biotechnol. 28: 891-99.

20- KLOEPPER, J.W. Y SCHROTH, M.N. 1981. Plant growth-promoting rhizobacteria and plant growth under gnotobio conditions. Phytopathology 71:642-644.

21- KNOWLES, M. M., PABÓN, M. L., Y CARULLA, J. E. 2012. Use of cassava (Manihot esculenta Crantz) and other starchy non-conventional sources in ruminant feeding. Rev Colom de Cienc Pecua 25(3): 488-499.

22- KUMAR, M.; BAISHAYA, L. K.;GHOSH, D. C.; GUPTA, V. K.; DUBEY, S. K.; DAS, A. Y PATEL, D. P. 2012. Productivity and soil health of potato (Solanum tuberosum L.) field as influenced by organic manures, inorganic fertilizers and biofertilizers under high altitudes of eastern Himalayas. J Agric Sci 4(5): 223. 
23- KUSHWAH, S. S. Y BANAFAR, R. N. S. 2003. Influence of different $N$ and $P$ levels with and without bio-fertilizer on N, P content, uptake and yield of potato cv. Kufri Jyoti. J. Indian Potato Assoc 30(3-4): 321-324.

24- LATHAM, M. C. 2002. Macronutrientes: carbohidratos, grasas y proteínas. Colección FAO. Nutrición humana en el mundo en desarrollo №29. pp 531. Roma (Italia). FAO. [online] Disponible en: http://www.fao.org/docrep/006/ w0073s/w0073s00.htm. Acceso: 07/09/2017.

25- MANDAL, R.C. 1993 Tropical Root and Tuber Crops. India, Agrobotanical Publishers. 396 p.

26- MALIK, D.K. Y SINDHU, S.S. 2011. Production of indole acetic acid by Pseudomonas sp: effect of coinoculation with Mesorhizobium sp. Cicer on nodulation and plant growth of chickpea (Cicer arietinum). Physiol. Mol. Biol. Plants 17: 25-32.

27-MARRERO, M.A.,; AGARAS, B.; WALL, L. G. Y VALVERDE, C. 2015. Enriquecimiento diferencial de Pseudomonas spp. en el rizoplano de distintas especies cultivadas. Rev Argent Microbiol 47(2): 132-137.

28- MORENO, L. Y. Y GALVIS F. 2013. Potencial biofertilizante de bacterias diazótrofas aisladas de muestras de suelo rizosférico. Rev Pastos y Forrajes 36(1): 33-37.

29- NOAR, J. D., Y BRUNO-BÁRCENA, J. M. 2018. Azotobacter vinelandii: the source of 100 years of discoveries and many more to come. Microbiology 164: 421-436.

30- NTC 5122. Norma Técnica Colombiana. 2002. Alimentos para animales. Determinación del contenido de fibra cruda. Método con filtrado intermedio.

31- PÉREZ, D. J. Y CAMPO, R. O. 2017. Efecto de la densidad poblacional sobre el rendimiento de ñame espino (Dioscorea rotundata Poir.) tipo exportación. Rev Col Cienc Hortic 10(1): 89-98.

Revista FAVE - Ciencias Agrarias 17 (1) 2018
32- RAM, C. J. 2015. Biofertilizer options in nutrient management of potato. Int J Recent Sci Res 4(1): 420-421.

33- RODRÍGUEZ, W. 2000 Botánica, domesticación y fisiología del cultivo del ñame (Dioscorea alala). Agronomía Mesoamericana 11 (2):133-152.

34- ROJAS, J. M.; ROMERO, D. M.; CRISTALES, M. D. R. B.; ANDRADE, O. R.; GARCÍA, Y. E. M.; SAENZ, Y. S. Y LUCIO, M. C. 2016. Mecanismos de fitoestimulación por rizobacterias, aislamientos en América y potencial biotecnológico. Rev Biol 17(2): 24-34.

35- ROJAS, D.; CONTRERAS, M. Y SANTOYO, G. 2013. Mecanismos de estimulación del crecimiento vegetal en bacterias del género Bacillus. Biológicas 15:36-41.

36- SÁNCHEZ, L.D. Y PÉREZ, P. J. 2018. Caracterización y evaluación de pgprs sobre el crecimiento de plántulas de Dioscorea rotundata in vitro. Agr. Costarricense 42(2):75-91.

37- SON, H. J.; KIM, Y. G. Y LEE, S.J. 2003. Isolation, identification and physiological characteristics of biofertilizer resources, insoluble phosphate-solubilizing bacteria. Korean J. microbiol (30):51-55.

38- TAHIR, M.; MIRZA, M.S.; ZAHEER, A.; DIMITROV, M.R.; SMIDT, H. Y HAMEED, S. 2013. Isolation and identification of phosphate solubilizer Azospirillum, Bacillus and Enterobacter strains by 16SrRNA sequence analysis and their effect on growth of wheat (Triticum aestivum L.). Aus. J. Crop. Sci 7: 1284-1292.

39- VALLEJO, M.; CORREA, C. R. B. Y CASTILLA L. 2008. Evaluación de la asociación bacterias fijadoras de nitrógeno-líneas interespecíficas de arroz-nitrógeno, en Typic haplustalf. Ibagué. Colombia. Acta Agron 57(1): 43-49.

40- YASMIN, F.; OTHMAN, R.; SIJAM, K. Y SAAD, M. S. 2007. Effect of PGPR inoculation on growth and yield of sweetpotato. J. Biol. Sci 7(2): 421-424. 